\title{
On numerical solution of fractional order boundary value problem with shooting method
}

\author{
Hüseyin Demir ${ }^{1, *}$, Yücel Baltürk ${ }^{2}$ \\ ${ }^{1}$ Ondokuz Mayıs University, Institute of Science, Department of Mathematics, 55139, Samsun, \\ Turkey \\ ${ }^{2}$ Ondokuz Mayıs University, Institute of Science, Department of Mathematics, 55139, Samsun, \\ Turkey
}

\begin{abstract}
In this study the shooting method is used for calculation of the second order boundary value problem with fractional order. This method is found to be useful for the application. The accuracy of the shooting method is tested. Some examples are given to illustrate the efficiency of the method with respect to different value of fractional orders.
\end{abstract}

\section{Introduction}

The history of fractional calculus and fractional differential equations date back to 1695 (refer to [6] for a brief history). Studies on fractional calculus goes back to studies on calculus [11]. Numerous publications relevant with fractional differential equations have been published in time. Some of them are [1]-[4], [7], [8], [10]. Also some important books on fractional field can remark as [3] and [7]. Related with our subject, Mohamed and Mahmoud have investigated fractional Euler's method and modified trapezoid rule in ([7]). Additionally Tong, Feng and LV have also investigated the error analysis of the fractional Euler's method in ([9]).

In this study a second order boundary value problem (9) is considered. First of all this BVP has been solved analytically and evaluated the value of this exact solution at the certain $h$ points. Then the shooting method has been used to evaluate the numerical solution of this boundary value problem by using the formula (7)-(8) which is given in ([7]). During the application of the shooting method, for predictor the fractional Euler method and for corrector the modified trapezoid rule for systems has been applied to solve the system of IVP (10)-(11). This solution has implemented by taking $m=1, n=1$ and we have seen that the solution values of the shooting method are compatible with exact solution values at the same $h$ point. Then the calculations have been repeated with different $m, n$ values which are fractional orders. Consequently the results was have been submitted in a table.

\footnotetext{
* Corresponding author: hdemir@omu.edu.tr
} 


\section{Shooting method}

For the use of the shooting method, firstly need the changing of the boundary value problem to system of initial value problems and then need to assume a guess value at the lower bound of the interval. After these, the solution goes on like the solution of system of differential equations.

Let us consider a second order boundary value problem

$$
p^{\prime \prime}=f\left(t, p, p^{\prime}\right), \phi \leq t \leq \psi
$$

with

$$
p(\phi)=\gamma, y(\psi)=\eta
$$

boundary conditions.

At first boundary value problem, which is given, is converted to two first order differential equation:

$$
\begin{array}{ll}
\left\{\begin{array}{ll}
\frac{d p}{d t}=p^{\prime}=r \\
r=g(t, p, r)
\end{array},\right. & p(\phi)=\gamma \\
\frac{d r}{d t}=k(t, p, r), & r(a)=\omega
\end{array}
$$

After deciding the $h$ step size we use one of the known methods like Euler, RungeKutta, etc. to solve these equations. Then we gain the first numerical result of the BVP that we consider subject to the first guess value $\omega$. The solution is valid if the solution is enough closer to the upper bound $\eta$, else the procedure will repeat with another guess.

After two guesses, instead of making the third guess arbitrary, we can use the interpolation to obtain the third and if necessary the next guesses [5].

\section{For predictor the Fractional Euler method and for corrector the Modified Trapezoid Rule formula for systems}

In this section the basic formula for the numerical solution of the system of fractional differential equations will be given. Let us consider the system of

$$
\begin{gathered}
D_{*}^{m} p(x)=g(x, r(x)), \quad p\left(x_{0}\right)=p_{0}, \\
D_{*}^{n} r(x)=k(x, p(x)), \quad r\left(x_{0}\right)=r_{0}, \quad 0<m, n<1
\end{gathered}
$$

fractional differential equations. To solve this system numerically the basic formula that we use is: 


$$
\begin{aligned}
& p\left(x_{s}\right)=\frac{h^{m}}{\Gamma(m+2)}\left((s-1)^{m+1}-(s-m-1) s^{m}\right) g\left(x_{0}, r\left(x_{0}\right)\right)+p\left(x_{0}\right)+ \\
& \frac{h^{m}}{\Gamma(m+2)} \sum_{q=1}^{s-1}\left((s-q+1)^{m+1}-2(s-q)^{m+1}+(s-q+1)^{m+1}\right) g\left(x_{q}, r\left(x_{q}\right)\right)+ \\
& \frac{h^{m}}{\Gamma(m+2)} g\left(x_{s}, r\left(x_{s-1}\right)+\frac{h^{m}}{\Gamma(m+1)} g\left(x_{s-1}, r\left(x_{s-1}\right)\right)\right) \\
& r\left(x_{s}\right)=\frac{h^{n}}{\Gamma(n+2)}\left((s-1)^{n+1}-(s-n-1) j^{n}\right) k\left(x_{0}, p\left(x_{0}\right)\right)+r\left(x_{0}\right)+ \\
& \frac{h^{n}}{\Gamma(n+2)} \sum_{q=1}^{s-1}\left((s-q+1)^{n+1}-2(s-q)^{n+1}+(s-q+1)^{n+1}\right) k\left(x_{q}, p\left(x_{q}\right)\right)+ \\
& \frac{h^{n}}{\Gamma(n+2)} k\left(x_{s}, p\left(x_{s-1}\right)+\frac{h^{n}}{\Gamma(n+1)} k\left(x_{s-1}, p\left(x_{s-1}\right)\right)\right)
\end{aligned}
$$

[7].

\section{Numerical example}

Example: Let us consider the

$$
\begin{aligned}
& \frac{d^{2} p}{d t^{2}}-p=0 \\
& p(0)=20, p(1)=100
\end{aligned}
$$

boundary value problem. Solve this problem with shooting method.

Solution: The exact solution of the boundary value problem is $p=39,416 e^{t}-19,416 e^{-t}$. At first we consider two initial value problems below.

$$
\begin{aligned}
& \frac{d p}{d t}=r=g(t, p, r), p(0)=20 \\
& \frac{d r}{d t}=p=k(t, p, r), r(0)=\omega=50
\end{aligned}
$$

The step size is $h=\frac{1-0}{4}=0.25$ and $m=1, n=1$. On the other hand the first guess value is obtained arbitrary as $\omega=50$. The result subject to first guess is 89.590 and so the solution is not correct. Next guess is the second arbitrary guess is $\omega=80$ and the result subject to second guess is 124.871 so the solution is not correct.

The third guess which is obtained by the interpolation of first and two guesses is $\omega=58.851$. The result subject to third guess is 99.999 and the solution is correct. 
Under these circumstances for numerical solution, the formula for predictor the fractional Euler method and for corrector the modified trapezoid rule for systems is used, by taking $m=1, n=1$. Further the results that obtained with the same procedure for the same example with different $m, n$ values were given in Table 1.

\begin{tabular}{|c|c|c|c|c|}
\hline$x$ & $\begin{array}{c}\text { Exact } \\
\text { Solution }\end{array}$ & $\begin{array}{c}\text { Numerical } \\
\text { solution for } \\
m=1, n=1\end{array}$ & $\begin{array}{c}\text { Numerical } \\
\text { solution for } \\
m=0.6, n=0.25\end{array}$ & $\begin{array}{c}\text { Numerical } \\
\text { solution for } \\
m=0.75, n=0.25\end{array}$ \\
\hline 0.25 & 35.490 & 36.551 & 26.67655019 & 28.81987638 \\
\hline 0.5 & 53.209 & 53.550 & 48.74752752 & 49.05826313 \\
\hline 0.75 & 74.272 & 74.432 & 65.72867265 & 68.53210261 \\
\hline 1 & 100 & 99.999 & 100.0000003 & 100.0000000 \\
\hline
\end{tabular}

Table 1. Exact and numerical solution values of the example.

\section{Conclusion}

In this study a boundary value problem, which has exact solution is considered. The shooting method is used for the numerical solution of this boundary value problem. To solve the two initial value problems which arise when applying shooting method, the formula for predictor the fractional Euler method and for corrector the modified trapezoid rule for systems is used. Because of the incorrect solution values of the boundary value problem subject to arbitrary guesses the third guess is made by using the interpolation formula. The solution was repeated with this guess value. The results that obtained were compared with exact solution values and approximated the target value (the other boundary condition of boundary value problem) with high sensivity. Additionally, for different $m, n$ values, numerical solution values at certain $h$ points are in line with the exact solution values of the boundary value problem. Finally, the shooting method can be used for the numerical solution of the fractional order boundary value problem as a result of this consistence of the values in the Table 1.

\section{References}

1. T.S. Alaroev, H.T. Alaroeva, N.M. Nie and Y.F. Tang, Mem. on Diff. Eq. and Math. Phys. Boundary Value Problems For Differential Equations Of Fractional Order, 49, 21-82 (2010)

2. M. Benchohra, S. Hamani, and S.K. Ntouyas, Surv. in Math. and its App. Boundary Value Problems for Differential Equations with Fractional Order, 3, 1-12 (2008)

3. K. Diethelm, The Analysis of Fractional Differential Equations, Berlin: Springer, (2004)

4. A. Doğan, "Kesirli Mertebeden Diferansiyel Denklemler ve Sayısal Çözümleri Üzerine Bir Çalışma”, Yüksek Lisans Tezi. Ankara: Gazi Üniversitesi, (2011)

5. İ. Karagöz, Sayısal Analiz Ve Mühendislik Uygulamaları, Ankara: Nobel, (2011)

6. A. Loverrro, Fractional Calculus: History, Definitions and Applications for the Engineer, Department of Aerospace and Mechanical Engineering University of Notre Dame, (2004).

7. D.A.S. Mohamed, and R.A. Mahmoud, Int. Jou. of Comp. App. An Algorithm For The Numerical Solution of System of Fractional Differential Equations, ,65, 27-31 (2013).

8. I. Podlubny, Fractional Differential Equations, San Diego, California: Academic Press, (1999). 
9. P. Tong, Y. Feng, H. LV, Wseas Trans. on Math., Eulers Method for Fractional Differential Equations, 12, 1146-1153, (2013).

10. V. Turut, "Kesirli Diferansiyel Denklemlerin Nümerik Çözümleri”, Doktora Tezi. İstanbul: Yıldız Teknik Üniversitesi, (2010).

11. M. Weilbeer, Efficient Numerical Methods for Fractional Differential Equations and their Analytical Background, Von der Carl-Friedrich-Gauß-Fakultät für Mathematik und Informatik der Technischen Universität Braunschweig, (2005). 